\title{
Effect of Lifestyle Modification Program Implemented in the Community on Workers' Job Satisfactiona
}

\author{
Masanori OHTA $^{1 *}$, Chieko TAKIGAMI ${ }^{1}$ and Masaharu IKEDA ${ }^{2}$ \\ ${ }^{1}$ Department of Health Development, Institute of Industrial Ecological Sciences, University of Occupational and \\ Environmental Health, 1-1 Iseigaoka, Yahatanishi-ku, Kitakyushu 807-8555, Japan \\ ${ }^{2}$ Kitakyushu Tsuyazaki Hospital, 1693 Watari, Fukutsu 811-3307, Japan
}

Received June 30, 2006 and accepted November 2, 2006

\begin{abstract}
It is important for occupational health to justify the impact of health promotion programs on job satisfaction, which is associated with work-related outcomes. The aim of this study is to estimate the effects of lifestyle modification activity implemented by the community on job satisfaction, and to analyze the factors which contributed to the improvement of workers' job satisfaction. A lifestyle modification program consisting of aerobic exercise and diet counseling was conducted for 12 wk in the community. Data on 264 workers were obtained before and after the intervention. The subjects were asked to fill out questionnaires about work-related items, lifestyle, and mental health status. In addition to the ameliorations of GHQ, lifestyle, subjective complaints, and the risk factors of lifestyle-related diseases, an improvement in workers' job satisfaction was shown by the participation in the community-based lifestyle modification program. For analyzing factors which contributed to the improvement in job satisfaction, logistic regression analysis was employed. Refreshment from fatigue by sleep independently contributed to the improvement of job satisfaction even after adjusting for the other variables. The health promotion program implemented in the community may be useful for workers' job satisfaction especially through the dissipation of fatigue by refreshment sleep.
\end{abstract}

Key words: Community-based health promotion, Job satisfaction, Lifestyle modification, Refreshment, Collaboration

\section{Introduction}

According to a report issued by the WHO expert committee on health promotion in the workplace, "Health promotion is a continuum ranging from the treatment of disease, to the prevention of disease including protection against specific risks, to the promotion of optimal health. Achieving optimal health includes improving physical abilities in relation to sex and age, improving mental ability, developing reserve capacities and adaptability to changing circumstances of work and life, and reaching new levels of individual achievement in creative and other work. In

aPresented at the $13^{\text {th }}$ International Congress on Occupational Health Services, November 30 - December 3, 2005, Utsunomiya, Japan.

*To whom correspondence should be addressed. a work setting these health indicators may be evaluated quantitatively by indices of absenteeism, job satisfaction, and work stability." ") Job satisfaction is defined as a pleasurable or positive emotional state resulting from the appraisal of one's job experiences as fulfilling important job values ${ }^{2}$. Since job satisfaction has been related to absenteeism ${ }^{3)}$, job stress ${ }^{4)}$, and quality of life ${ }^{5)}$, it is important for occupational health to justify the impact of health promotion programs on job satisfaction.

A recent review of workplace physical activity programs, however, reported some evidence of reduced absenteeism, inconclusive evidence of an effect on job satisfaction, job stress and employee turnover, and no evidence of a positive effect on productivity ${ }^{6}$. Peterson et al. reported that only regular exercise behavior, independent of participation in 
the worksite health promotion program, was found to differentiate job-satisfaction scores ${ }^{7}$. Since physical activity may have beneficial effects not only on physical health ${ }^{8-11}$ but also on mental health ${ }^{12-17)}$, acquirement of exercise habits might be expected to enhance the job satisfaction even if the approach was from the community and not from the worksite. In the present study, we estimated the effects of lifestyle modification activity implemented by the community on job satisfaction, and analyzed the factors which contributed to the improvement of workers' job satisfaction.

\section{Participants and Methods}

\section{Design}

This study employed an interventional before-after research. Measurements were made at baseline and again within a week after the 12-wk intervention to evaluate the effect of the program. The protocol was approved by the ethics committee of the University of Occupational and Environmental Health.

\section{Participants}

Four hundred sixty-eight workers voluntarily participated in a 12-wk lifestyle modification program focused on the prevention of lifestyle-related diseases conducted by the Kitakyushu Municipal Health Promotion Committee. The authors obtained the written informed consent of each participant before the start of the program. However, 204 participants were eventually excluded and they comprised: 57 who dropped out of the program, 77 who did not wish to be considered as subjects although they completed the program, and 70 who provided incomplete information for one or more items analyzed. The final study group thus consisted of 264 workers (men 77, women 187; mean age, $49.7 \pm 10.7 \mathrm{yr}$ ).

\section{Lifestyle modification \\ Exercise training}

To estimate maximum oxygen consumption ( $\left.\dot{\mathrm{V}}_{2} \max \right)$ and to determine suitable exercise intensity for mild exercise, a four-stage graded submaximal test was performed using a cycle ergometer (ML-1800; Fukuda Electronics; Tokyo, Japan). The mild exercise consisted of a 10-min stretching session followed by $60 \mathrm{~min}$ on aerobic exercises such as a cycle ergometer, indoor walking, and low-impact aerobics. Subjects were instructed to check their own pulse rate on their radial artery and to exercise at a prescribed pulse rate corresponding to an intensity of $50 \% \dot{\mathrm{V}}_{2} \max$ or the anaerobic threshold point. Registered trainers and doctors supervised the exercises and the subjects were advised to maintain their target heart rate. The subjects participated in the above exercise sessions twice a week.

\section{Diet}

Subjects completed a self-administered questionnaire on dietary habits (WELL-200; Fukuda Electronics; Tokyo, Japan) before and after the intervention ${ }^{18}$. We estimated total calorie intake, contribution of protein, fat and carbohydrate to total calorie intake, salt intake, vitamins intake, iron intake, calcium intake, and so on according to their answers on the questionnaire. Based on the information before the intervention, personal diet counseling was provided by registered dietitians at the baseline and $6 \mathrm{wk}$ thereafter. Such diet counseling in general included instructions not to eat snacks, to limit alcohol and/or high-calorie beverage consumption, to reduce fatty foods, and to restrict salt intake. Four to eight objectives were then established for each participant and their answers to this questionnaire were used for guidance. The subjects were encouraged to meet their objectives, and kept a daily record of their progress.

\section{Questionnaires}

The subjects were asked to fill out questionnaires (Well200, Fukuda Electronics; Tokyo, Japan) about work-related items, lifestyle, and mental health status (Table 1). Workrelated items consisted of job satisfaction (measured by the following scores 1 . very satisfied, 2. satisfied, 3. neither, 4 . dissatisfied, 5. very dissatisfied), physical activity during commute to work and at worksite, and subjective complaints such as stiff neck and low back pain (measured by the following scores 1. almost never, 2. sometimes, 3. often). Lifestyle items consisted of sleeping (measured by the following scores about two items (A) sleepless 1. always, 2. often, 3. sometimes, 4. seldom, 5. never and (B) refreshment from fatigue 1 . fully, 2. relatively, 3. hard to say, 4. not fully, 5. not at all), exercise habits at leisure time, frequency of alcohol consumption (measured by the following scores 1 . everyday, 2. almost everyday, 3 . frequently ( 4 or $5 / \mathrm{wk}$ ), 4 . sometimes ( 2 or $3 / \mathrm{wk}$ ), 5 . seldom (once a week), 6. almost never), and smoking (measured by the following scores 1. never smoked, 2. ex-smoker, 3. current smoker). The scores of questionnaires were converted into a global score on a scale of 100, and higher scores indicate better lifestyle. As for subjective complaints, higher scores indicate more frequency of episodes. With regard to job satisfaction which is the main outcome of our study, the validity of a single-item measure has been demonstrated by many studies reported to date ${ }^{19-22)}$. Mental health status was accessed with the 12-item version General Health 
Table 1. Questionnaires categories of measurement items*

\begin{tabular}{ll}
\hline Major items & Contents \\
\hline $\begin{array}{l}\text { Work-related items } \\
\text { Job satisfaction } \\
\text { Physical activity }\end{array}$ & \\
Subjective symptoms & $\begin{array}{l}\text { During commute to work } \\
\text { At worksite } \\
\text { Stiff neck } \\
\text { Low back pain }\end{array}$ \\
Lifestyle items & Sleepless \\
Sleeping & Refreshment from fatigue \\
Alcohol Consumption & \\
Smoking status & \\
Exercise Habits at leisure time & \\
Mental health & GHQ 12-item version \\
& Coping with stress \\
\hline
\end{tabular}

GHQ: General Health Questionnaire.

*Details were described in the text.

Questionnaire (GHQ), and through the question about 'whether you are coping effectively with stress (measured by the following scores 1. yes, 2. no)'. According to Goldberg's method ${ }^{23)}$, four response options (1-2-3-4) were given scores of $0-0-1-1$, and total score was calculated by summing these scores for each person. Higher scores indicate higher psychological distress.

\section{Measurement of anthropometries and plasma biochemical parameters}

The height, weight and blood pressure of the subjects were measured before and after the intervention. The body mass index (BMI) of the subjects were calculated as body weight $(\mathrm{kg}) /(\text { body height }(\mathrm{m}))^{2}$. Blood samples were collected after at least $12 \mathrm{~h}$ of nocturnal fasting. Plasma samples were used for measurements of fasting plasma glucose, insulin, total cholesterol (TC), and HDL cholesterol (HDL-C). The homeostasis model of assessment of insulin resistance (HOMA-IR: fasting plasma glucose $\mathrm{x}$ insulin/405) and TC/ HDL-C ratio were calculated, respectively.

\section{Statistical analysis}

To evaluate the effect of lifestyle modification, Wilcoxon's test was used. For analyzing factors which contributed to the improvement of job satisfaction, multivariate logistic regression analysis was employed. All statistical calculations were performed with personal computer statistical software (STATVIEW 5.0; SAS Institute Inc., Cary, USA). All results are expressed as the mean \pm SD. Values of $p<0.05$ were considered to indicate statistical significance.

\section{Results}

Table 2 shows demographic data on the participants such as job status and full-time or part-time staff. The majority of the participants were full-time workers in non-executive posts.

Table 3 showed the effects of lifestyle modification on lifestyle and work-related outcomes. In addition to the ameliorations of GHQ, lifestyle, subjective complaints, BMI, blood pressure, $\mathrm{VO}_{2} \max$, and TC/HDL-C ratio, the improvement in workers' job satisfaction was shown by the participation in the community-based lifestyle modification program. The items depending on worksite management such as working hours and regularity of dinner were not changed through the community-based health promotion activity (data not shown). We analyzed factors which contributed to the improvement of job satisfaction. The job satisfaction improvement was defined as those who increased their score of job satisfaction by our intervention. Refreshment from fatigue (odds ratio 2.06; 95\% Conference Intervals 1.09-3.09) independently contributed to the improvement of job satisfaction even after adjusting for the other variables (Table 4).

\section{Discussion}

The present study represented that the health promotion program consisting of aerobic exercise and diet counseling improved the job satisfaction in addition to the risk factors of lifestyle-related diseases. Peterson et al. analyzed the impact of a worksite health promotion program on job satisfaction, and indicated that insofar as job satisfaction is concerned, job design and the psychosocial aspects of the work environment may be more influential than a health promotion program ${ }^{7}$. Multiple logistic regression analysis showed that refreshment from fatigue by sleep contributed to the improvement of job satisfaction after adjusting for the improvement of lifestyle, mental health, and risk factors for lifestyle-related diseases. Eriksen et al. indicated that sleeping problems were a predictor of long-term work disability ${ }^{24}$. Our health promotion program indicated the effects on sleeping quality, investigating whether subjects were sleeping well and whether they experienced relief from the previous day's fatigue following sleep. There are some reports indicating the relationship between fatigue and job dissatisfaction ${ }^{25-27)}$. Sleeping is thought to be important for improvement of mental health and for refreshment from fatigue, resulting in improvement of job satisfaction. 
Table 2. Job characteristics of participants

\begin{tabular}{|c|c|c|c|c|}
\hline & & $\begin{array}{l}\text { Overall } \\
\mathrm{N}=264\end{array}$ & $\begin{array}{c}\text { Men } \\
\mathrm{N}=77\end{array}$ & $\begin{array}{l}\text { Female } \\
\mathrm{N}=187\end{array}$ \\
\hline \multicolumn{2}{|c|}{ Age (years old, mean $\pm \mathrm{SD}$ ) } & $49.7 \pm 10.7$ & $50.3 \pm 10.7$ & $49.5 \pm 10.7$ \\
\hline \multirow[t]{2}{*}{ Job status } & Executives & 14 & 13 & 1 \\
\hline & Others & 250 & 64 & 186 \\
\hline \multirow[t]{2}{*}{ Working form } & Full-time worker & 240 & 72 & 168 \\
\hline & Part-time worker & 24 & 5 & 19 \\
\hline
\end{tabular}

Table 3. Effects of intervention on lifestyle, work-related items, mental health, and risk factors of lifestyle-related diseases

\begin{tabular}{|c|c|c|c|}
\hline \multirow[b]{2}{*}{ Variables } & Before & After & \multirow[b]{2}{*}{$p$ value } \\
\hline & Mean SD & Mean SD & \\
\hline BMI & $23.9 \pm 3.3$ & $23.5 \pm 3.2$ & $<0.0001$ \\
\hline SBP & $132.1 \pm 18.0$ & $125.8 \pm 17.4$ & $<0.0001$ \\
\hline DBP & $80.1 \pm 11.1$ & $77.1 \pm 10.9$ & $<0.0001$ \\
\hline$\dot{\mathrm{V}}_{2} \max$ & $32.3 \pm 6.0$ & $34.7 \pm 5.8$ & $<0.0001$ \\
\hline HOMA-IR & $2.2 \pm 3.5$ & $2.1 \pm 2.5$ & 0.56 \\
\hline TC/HDL-C ratio & $3.4 \pm 0.9$ & $3.3 \pm 0.9$ & $<0.0001$ \\
\hline \multicolumn{4}{|l|}{ Questionnaires } \\
\hline GHQ score & $2.0 \pm 2.5$ & $1.4 \pm 2.3$ & $<0.0001$ \\
\hline Coping ways with stress & $85.4 \pm 22.8$ & $90.3 \pm 19.8$ & $<0.0001$ \\
\hline Sleepless & $78.3 \pm 19.0$ & $82.0 \pm 18.9$ & $<0.0001$ \\
\hline Refreshment from fatigue & $63.8 \pm 20.4$ & $70.3 \pm 19.1$ & $<0.0001$ \\
\hline Smoking habit & $88.3 \pm 21.6$ & $89.3 \pm 21.3$ & 0.04 \\
\hline Frequency of alcohol consumption & $77.9 \pm 26.9$ & $79.8 \pm 25.2$ & 0.0003 \\
\hline Job satisfaction & $67.4 \pm 16.3$ & $70.0 \pm 15.9$ & 0.002 \\
\hline Physical activity during commute & $51.1 \pm 25.4$ & $56.6 \pm 26.2$ & $<0.0001$ \\
\hline Physical activity at worksite & $17.1 \pm 9.6$ & $18.4 \pm 10.5$ & 0.02 \\
\hline Exercise habits at leisure time & $20.2 \pm 9.8$ & $26.2 \pm 10.5$ & $<0.0001$ \\
\hline \multicolumn{4}{|l|}{ Subjective complaints } \\
\hline Stiff neck & $65.0 \pm 24.5$ & $58.0 \pm 23.8$ & $<0.0001$ \\
\hline Low back pain & $57.1 \pm 23.6$ & $52.4 \pm 22.9$ & 0.001 \\
\hline
\end{tabular}

BMI: body mass index, SBP: systolic blood pressure, DBP: diastolic blood pressure, $\mathrm{VO}_{2}$ max: maximum oxygen consumption, HOMA-IR: homeostatic model for insulin resistance, TC/HDL-C ratio: total cholesterol/high-density lipoprotein cholesterol ratio, GHQ: general health questionnaire

The scores of questionnaires except for GHQ were converted into a global score on a scale of 100 , and higher scores indicate better lifestyle. As for subjective complaints, higher scores indicate more frequency of episodes. Wilcoxon's test.

It is worth noting that the health promotion activities for workers in this study were implemented not in the workplace but in the community. The project originated with our study to verify the effects of lifestyle modification according to a request by the municipal government in 1995 . When this program was implemented as a health promotion activity in community health in 1999 , the head of relevant labor standards supervision office was involved in the organizing committee, under which the planning and the efforts toward health promotion for workers were included. A previous study reported that participation in the worksite health promotion program did not influence job satisfaction scores, while there was a significant difference in job satisfaction for those who exercised regularly for the past six months, compared with those who did not ${ }^{7}$. Utilizing the communitybased health promotion activities might enhance exercise regularity and therefore job satisfaction.

In 1988, Japanese Government revised the Industrial Safety 
Table 4. Result of multivariate logistic regression analysis for improvement of job satisfaction by lifestyle modification

\begin{tabular}{|c|c|c|c|c|}
\hline & & OR & $95 \% \mathrm{CI}$ & $p$ value \\
\hline Age & age & 1.00 & $0.97-1.03$ & 0.981 \\
\hline \multirow[t]{2}{*}{ Gender } & men & & & \\
\hline & women & 0.66 & $0.33-1.33$ & 0.244 \\
\hline \multirow[t]{5}{*}{ Percent change of } & BMI & 0.98 & $0.86-1.11$ & 0.737 \\
\hline & SBP & 1.01 & $0.98-1.05$ & 0.479 \\
\hline & $\dot{\mathrm{V}}_{2} \max$ & 1.00 & $0.97-1.03$ & 0.983 \\
\hline & HOMA-IR & 1.00 & $1.00-1.01$ & 0.336 \\
\hline & TC/HDL-C ratio & 0.99 & $0.97-1.02$ & 0.614 \\
\hline \multicolumn{5}{|l|}{ Questionnaires } \\
\hline \multirow[t]{2}{*}{ GHQ } & not improved & 1.00 & (reference) & \\
\hline & improved & 1.23 & $0.66-2.28$ & 0.515 \\
\hline \multirow[t]{2}{*}{ Coping ways with stress } & not acquired & 1.00 & (reference) & \\
\hline & acquired & 1.85 & $0.82-4.17$ & 0.138 \\
\hline \multirow[t]{2}{*}{ Sleepless } & not improved & 1.00 & (reference) & \\
\hline & improved & 1.26 & $0.65-2.46$ & 0.493 \\
\hline \multirow[t]{2}{*}{ Refreshment from fatigue } & not improved & 1.00 & (reference) & \\
\hline & improved & 2.06 & $1.09-3.89$ & 0.025 \\
\hline \multirow[t]{2}{*}{ Smoking habit } & not improved & 1.00 & (reference) & \\
\hline & improved & 0.85 & $0.20-3.58$ & 0.820 \\
\hline \multirow[t]{2}{*}{ Frequency of alcohol consumption } & not improved & 1.00 & (reference) & \\
\hline & improved & 0.88 & $0.40-1.90$ & 0.738 \\
\hline \multirow[t]{2}{*}{ Physical activity during commute } & not increased & 1.00 & (reference) & \\
\hline & increased & 0.75 & $0.39-1.42$ & 0.378 \\
\hline \multirow[t]{2}{*}{ Physical activity at worksite } & not increased & 1.00 & (reference) & \\
\hline & increased & 0.91 & $0.46-1.80$ & 0.780 \\
\hline \multirow[t]{2}{*}{ Exercise habits at leisure time } & not increased & 1.00 & (reference) & \\
\hline & increased & 0.76 & $0.40-1.44$ & 0.399 \\
\hline \multicolumn{5}{|l|}{ Subjective Complaints } \\
\hline \multirow[t]{2}{*}{ Stiff neck } & not improved & 1.00 & (reference) & \\
\hline & improved & 0.78 & $0.38-1.60$ & 0.470 \\
\hline \multirow[t]{2}{*}{ Low back pain } & not improved & 1.00 & (reference) & \\
\hline & improved & 0.72 & $0.33-1.57$ & 0.439 \\
\hline
\end{tabular}

BMI: body mass index, SBP: systolic blood pressure, $\dot{\mathrm{V}}_{2}$ max: maximum oxygen consumption, HOMAIR: homeostatic model for insulin resistance, TC/HDL-C ratio: total cholesterol/high-density lipoprotein cholesterol ratio, GHQ: general health questionnaire, OR: odds ratio, 95\% CI: 95\% conference intervals.

and Health Law to promote health in the workplace, implementing the Total Health Promotion Plan (THP). According to a survey conducted in 2002 , only $8.0 \%$ of workplaces were implementing THP programs ${ }^{28)}$, but community-based health promotion activities are widely practiced by the local governments throughout the country ${ }^{29)}$ under a national primary health promotion campaign, Healthy Japan 21 (2000-2010). The Health Promotion Law came into force in May 2003 as the legal basis for supporting the campaign in Japan. Collaboration between community health and occupational health might be helpful for implementing health promotion activity especially in small and medium scale enterprises, which could not possess their own fitness facilities. Health promotion for workers in the community as the venue should be reevaluated for the improvement of job satisfaction in addition to the ameliorations of risk factors of lifestyle-related diseases.

Our study has several limitations. First, there was no control group in our study. Whether lifestyle modification program could contribute to job satisfaction needs to be examined in controlled studies. Second, since all participants were very motivated people in terms of healthy lifestyle, generalization of the present results need to be viewed with caution. Finally, although we considered occupational physical activity and subjective symptoms in analysis, we did not include other work-related measures such as their 
occupation in detail, the busy season and the presence or absence of major events during the intervention period.

\section{Conclusion}

The health promotion program implemented in the community may be useful for workers' job satisfaction especially through the dissipation of fatigue by refreshment sleep. Controlled studies are needed to confirm causality concerning health promotion program and job satisfaction.

\section{Acknowledgements}

We would like to express out gratitude to the staff of the Kitakyushu Municipal Health Promotion Center, and to Tomoyo Omae for her excellent technical assistance. This work was supported in part by a Grant-in-Aid for a UOEH Grant for Advanced Research (2005).

\section{References}

1) WHO Expert Committee: Health Promotion for Working Populations (1988) WHO Technical Report Series 765, WHO, Geneva.

2) Steinhardt MA, Dolbier CL, Gottlieb NH, McCalister KT (2003) The relationship between hardiness, supervisor support, group cohesion, and job stress as predictors of job satisfaction. Am J Health Promot 17, 382-9.

3) Mohren DC, Swaen GM, Kant I, van Schayck CP, Galama JM (2005) Fatigue and job stress as predictors for sickness absence during common infections. Int J Behav Med 12, 11-20.

4) Steinhardt MA, Dolbier CL, Gottlieb NH, McCalister KT (2003) The relationship between hardiness, supervisor support, group cohesion, and job stress as predictors of job satisfaction. Am J Health Promot 17, 382-9.

5) Evans DR, Pellizzari JR, Culbert BJ, Metzen ME (1993) Personality, marital, and occupational factors associated with quality of life. J Clin Psychol 49, 477-85.

6) Proper KI, Staal BJ, Hildebrandt VH, van der Beek AJ, van Mechelen W (2002) Effectiveness of physical activity programs at worksites with respect to work-related outcomes. Scand J Work Environ Health 28, 75-84.

7) Peterson M, Dunnagan T (1998) Analysis of a worksite health promotion program's impact on job satisfaction. J Occup Environ Med 40, 973-9.

8) Ekelund LG, Haskell WL, Johnson JL, Whaley FS, Criqui MH, Sheps DS (1988) Physical fitness as a predictor of cardiovascular mortality in asymptomatic North American men. The lipid Research Clinics Mortality Follow-up Study. N Engl J Med 319, 1379-84.

9) Paffenbarger RS Jr, Hyde RT, Wing AL, Lee IM, Jung DL, Kampert JB (1993) The association of changes in physical activity level and other lifestyle characteristics with mortality among men. N Engl J Med 328, 538-45.

10) Blair SN, Kohl HW 3rd, Barlow CE, Paffenbarger RS Jr, Gibbons LW, Macera CA (1995) Changes in physical fitness and all-cause mortality. A prospective study of healthy and unhealthy men. JAMA 273, 1093-8.

11) Friedenreich CM, Orenstein MR (2002) Physical activity and cancer prevention: etiologic evidence and biological mechanisms. J Nutr 132 (Suppl 11), 3456S-64S.

12) Paluska SA, Schwenk TL (2000) Physical activity and mental health: current concepts. Sports Med 29, 167-80.

13) Ross CE, Hayes D (1988) Exercise and psychologic wellbeing in the community. Am J Epidemiol 127, 762-71.

14) Stephens $T$ (1988) Physical activity and mental health in the United States and Canada: evidence from four population surveys. Prev Med 17, 35-47.

15) Camacho TC, Roberts RE, Lazarus NB, Kaplan GA, Cohen RD (1991) Physical activity and depression: evidence from the Alameda County Study. Am J Epidemiol 134, 220-31.

16) Paffenbarger RS Jr, Lee IM, Leung R (1994) Physical activity and personal characteristics associated with depression and suicide in American college men. Acta Psychiatr Scand Suppl 377, 16-22.

17) Farmer ME, Locke BZ, Moscicki EK, Dannenberg AL, Larson DB, Radloff LS (1988) Physical activity and depressive symptoms: the NHANES I epidemiologic follow-up study. Am J Epidemiol 128, 1340-51.

18) Okazaki T, Himeno E, Nanri H, Ikeda M (2001) Effects of a community-based lifestyle-modification program on cardiovascular risk factors in middle-aged women. Hypertens Res 24, 647-53.

19) Dolbier CL, Webster JA, McCalister KT, Mallon MW, Steinhardt MA (2005) Reliability and validity of a singleitem measure of job satisfaction. Am J Health Promot 19, 194-8.

20) Patrician PA (2004) Single-item graphic representational scales. Nurs Res 53, 347-52.

21) Wanous JP, Reichers AE, Hudy MJ (1997) Overall job satisfaction: how good are single-item measures? J Appl Psychol 82, 247-52.

22) Ramirez AJ, Graham J, Richards MA, Cull A, Gregory WM (1996) Mental health of hospital consultants: the effects of stress and satisfaction at work. Lancet 347, 724-8.

23) Goldberg D (1978) Manual of the general health questionnaire, 8-13, NFER-Nelson, Berkshire, UK.

24) Eriksen W, Natvig B, Bruusgaard D (2001) Sleep problems: a predictor of long-term work disability? A four-year prospective study. Scand J Public Health 29, 23-31.

25) Rafnsdottir GL, Gunnarsdottir HK, Tomasson K (2004) Work organization, well-being and health in geriatric care. Work 22, 49-55.

26) Andrea H, Beurskens AJ, Metsemakers JF, van Amelsvoort LG, van den Brandt PA, van Schayck CP (2003) Health problems and psychosocial work environment as predictors of long term sickness absence in employees who visited the occupational 
physician and/or general practitioner in relation to work: a prospective study. Occup Environ Med 60, 295-300.

27) de Croon EM, Blonk RW, de Zwart BC, Frings-Dresen MH, Broersen JP (2002) Job stress, fatigue, and job dissatisfaction in Dutch lorry drivers: towards an occupation specific model of job demands and control. Occup Environ Med 59, 356-61.
28) Japan Ministry of Labour (2003) A survey on health status of employees in 2002. Japan Ministry of Labour, Tokyo (in Japanese).

29) Japan Health Promotion \& Fitness Foundation. Healthy Japan 21. http://www.kenkounippon21.gr.jp/. Accessed September 18, 2006 (in Japanese). 